\title{
Cardiac mass in the left atrium: tumor or thrombus?
}

\section{Alma Sijamija ${ }^{1 *}$ Zumreta Kušljugić 2 Nermir Granov ${ }^{3}$ Omer Perva ${ }^{3}$ Alma Agačević1}

${ }^{1}$ Travnik General Hospital, Travnik, Bosnia and Herzegovina

2Public Health Institution University Clinical Center Tuzla, Tuzla, Bosnia and Herzegovina

${ }^{3}$ Clinical Center University of Sarajevo, Sarajevo, Bosnia and Herzegovina

\section{RECEIVED:}

March 31, 2015

ACCEPTED:

April 20, 2015

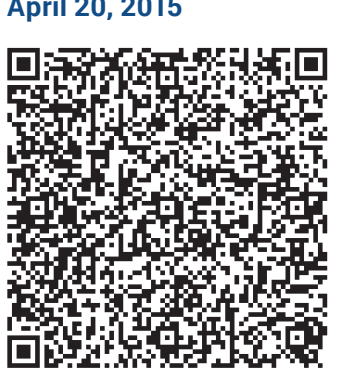

KEYWORDS: echocardiography, tumor, thrombus.

CITATION: Cardiol Croat. 2015;10(3-4):80. | DOI: http://dx.doi.org/10.15836/ccar.2015.80

ORCID: Alma Sijamija, http://orcid.org/0000-0003-2818-0501 • Zumreta Kušljugić, http://orcid.org/0000-0002-8565-776X • Omer Perva, http://orcid.org/0000-0003-2645-1558 • Alma Agačević, http://orcid.org/0000-0003-4671-0991

*ADDRESS FOR CORRESPONDENCE: Alma Sijamija, Javna ustanova Bolnica Travnik, Kalibunar bb, 72270 Travnik, Bosnia and Herzegovina. Phone: +387-61-780-085. E-mail: alma.sijamija@hotmail.com

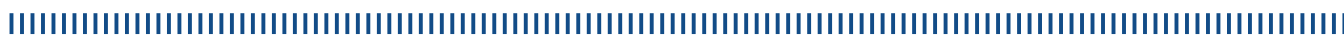

INTRODUCTION: Cardiac tumors can be primary (benign or malignant), with incidence from 0.002 to $0.3 \%$ according to autopsy reports, and secondary which are more common, found in about $5-10 \%$. The most common primary tumor of the heart is the myxoma. About $75 \%$ of all myxomas are located in the left atrium. They occur in all age groups, usually from the third to the sixth decade. They are more common in women, usually solitary, round tumors with a diameter of $10 \mathrm{~cm}$, uneven surfaces.

Thrombi in the left atrium are related to conditions associated with the blood stasis, such as atrial fibrillation, mitral valve disease, artificial mitral valve and dilated cardiomyopathy.

GOAL: To present the role of echocardiography in the diagnosis intracavitary cardiac mass.

CASE REPORT: 69-years-old female patient was brought to the hospital with symptoms of stroke, and history of moderate aortic stenosis with preserved EF 58\%. At the physical examination: precordial systolic murmur, blood pressure 220/120 mmHg. 12-lead ECG: atrial fibrillation, frequency 80/min, RBBB. Cranial CT confirmed hemorrhagic stroke and patient had permanent sequelae, motor aphasia. A year later, diabetes mellitus was verified. Three years after hospitalization, routine transthoracic echocardiogram was performed and it was observed tumor mass in the left atrium, inhomogeneous echo structure, size 29x62 mm, with narrow base attached to the bottom of the left atrium and with no repercussion on the function of the mitral valve; aortic valve: sclerotic with gradients of moderate stenosis; tricuspid valve: functional TR 2+ with PHT $60 \mathrm{mmHg}$; EF 53\%. The patient is presented to cardiosurgical team, who considering previous comorbidity, suggests conservative treatment. Due to the high risk of bleeding, oral anticoagulants were not included in therapy. Two years later (January 2015) patient was admitted to hospital, mixed ischemic-hemorrhagic stroke was confirmed with cranial $\mathrm{CT}$, with the lethal outcome.

CONCLUSION: Transthoracic echocardiogram is the method of choice in the diagnosis intracavitary cardiac mass. ${ }^{1-4}$ 2D echocardiography facilitates differentiation of thrombus and left atrial myxoma, including characterization of cardiac masses, in the case when additional diagnostics and therapy is not available.

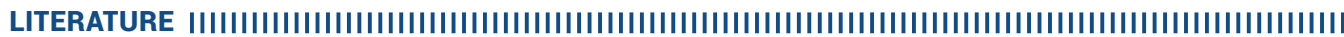

1. Sabatine MS, Colucci WS, Schoen FJ. Primary tumors of the heart. In: Braunwald E, Zipes DP, Libby P, eds. Heart Disease, 7th ed. Philadelphia: Elseviers Saunders; 2005: 1741.

2. Aggarwal SK, Barik R, Sarma TC, Iyer VR, Sai V, Mishra J, et al. Clinical presentation and investigation findings in cardiac myxomas. New insights from the developing world. Am Heart J. 2007;154(6):1102-7. http://dx.doi.org/10.1016/j.ahi.2007.07.032

3. Sugeng L, Lang RM. Atypical cardiac myxomas. Echocardiography. 2004;21(1):43-7. http://dx.doi.org/10.1111/1.0742-2822.2004.02124.x

4. Mügge A, Daniel WG, Haverich A, Lichten PR. Diagnosis of noninfective cardiac mass lesions by two-dimensional echocardiography: Comparison of the transthoracic and transesophageal aprroaches. Circulation. 1991;83(1):70-8. http://dx.doi.org/10.1161/01.CIR.83.1.70 